\title{
Training general practitioners in mental health skills
}

\author{
LINDA GASK and RICHARD MORRISS
}

The need for family doctors worldwide to receive training 'm mental health skills has been well documented. As Goldberg \& Gater (1996) recently commented on the implications for training of the findings of the World Health Organisation multicentre study (Üstün \& Sartorius 1995):

Changes need to be made to the way in which both undergraduates and vocational trainees are taught about mental disorders, so that teaching emphasises the psychological syndromes that general practitioners are likely to meet in their everyday work. Training packages need to be developed for primary care staff in the detection and management of mental disorders.

In the UK about $40 \%$ of British General Practitioners (GPs) train formally in a psychiatric post as part of the two years of specialist attachment in their training (Pereira Gray, 1995) but the training needs of future GPs are quite different from those of psychiatrists. A few months working in a psychiatric unit, where the focus is on the management of acute and chronic psychotic illness, does not appear to provide GPs in training with the knowledge and skills that they perceive that they will need for working in primary care (Williams, 1998). Similar comments could undoubtedly be made about the content of many undergraduate psychiatric curricula which continue to focus on the 'major' mental disorders, and fail to integrate mental health training with general hospital and general practice training where students may sea, but fail to recognise, any other patients with quite different types of mental disorder from those that they have learned about with their psychiatric attachment. Surveys of the perceived

Indirizzo per la corrispondenza: Dr. L. Gask, National Primary Care Research and Development Centre (NPCRDC), University of Manchester, Williamson Building, University of Manchester Oxford Road, Manchester M 13 9PL (UK).

Fax: + 44 1772.710772

E-mail: Linda.Gask@man.ac.uk training needs of experienced general practitioners in the UK also support the need for GP education that focuses on skill acquisition (Turton et al., 1995; Kerwick et al., 1997). Which skills are required?

In early work carried out in Manchester twenty years ago, Marks and colleagues showed that about $46 \%$ of the probable cases of emotional disorder being seen in primary care were missed by general practitioners (Marks et al., 1978). They found that both personality factors, and the behaviour of the doctor in the consultation, were important determinants of whether a patient's emotional distress was recognised. Ten key interviewing skills were described:

Early in the interview. Making good eye contact, clarifying the presenting complaint, using directive questions for physical complaints, beginning with open-ended questions and moving to closed questions later (the 'open to closed cone').

Throughout the interview. Making supportive or empathic comments, picking up verbal and non-verbal cues, not reading the notes dufing the taking of the history, dealing sensitively but effectively with overtalkativeness (being able to 'control' the interview) and asking fewer questions about past history. Given the greater likelihood of being able to change interviewing skills than effect change in personality attributes, work began to focus on the development of improved interviewing skills by means of videofeedback training (Goldberg et al., 1980).

This team then went on to examine interactive effects between the doctor and patient. Davenport et al. (1987) demonstrated that doctors who were good identifiers of emotional distress (doctors with a high 'Identification Index' or 'high II' for short) influenced the rate at which cues indicative of emotional distress were emitted by the patient. Doctors who were poor identifiers (or 'low II'), somehow suppressed the rate at which cues were emitted. Further work (Goldberg et al., 1993) delineated a set of behaviours which lead to increased cue emission and 
which are practised more frequently by able identifiers, and other behaviours which decrease cue emission and are less frequently practised by this group. There was also evidence that 'patient-led' interviews lead to greater cue emission than 'doctor-led' interviews. However, the findings were complicated by the fact that there were other behaviours which were only associated with increased cue emission when practised by able identifiers and not by poor identifiers. This suggested that the usefulness of the behaviour depended on the strategy that the doctor was following in displaying the behaviour. It is no use learning skills in isolation without considering the pattern of the interview and the rationale behind their use.

The training packages that were informed by this research have therefore focused not only on teaching basic communication skills (Gask et al., 1987; 1988) but also on the development of simple and transferable assessment and management strategies for commonly occurring problems in primary care practice, as originally described by Lesser (1985). This has led to production of packages to teach specific skills for management of patients with somatic presentation of emotional distress (Goldberg et al., 1989), depression (Gask et al., 1998), alcohol problems (Lewis \& Gask, 1994), anxiety (Morriss et al., 1999a) and those who are at risk of suicide or deliberate selfharm (Morriss et al., in press). These have proved more acceptable to many doctors than interventions designed primarily to improve their interviewing skills. We find that GPs often perceive their skills, despite much evidence to the contrary, as quite satisfactory. Training packages produced so far go some way to meeting the perceived needs of both the GPs in training who attend our courses (Ratcliffe et al., in press) and experienced GP in the broader community (Kerwick et al., 1997). However, we recognise a need for development of further training packages covering such diverse topics as managing psychiatric emergencies, dealing with potentially violent patients, managing psychosexual problems and talking to parents and children during the consultation.

In evaluating the effectiveness of any educational intervention in primary care it is essential to ask three key questions. Does the intervention bring about a change in clinician behaviour? Does this change, if it occurs, subsequently result in improved clinical, social or economic outcome? Does the intervention improve the morale or confidence of the GP?

Changes in clinician behaviour can be assessed under either controlled role-played conditions or in real life consultations between GP and patient. In the former an actor plays a patient consulting a GP before and after training. A rater, who is blind as to whether the videotaped role-played consultation with the GP occurred before or after training, determines the presence or absence of specific clinician behaviours (Gask et al., 1987; 1988; 1989; 1998; Bowman et al., 1992; Kaaya et al., 1992). This type of study is especially useful when patients present relatively rarely e.g. patients who are at significant suicide risk. However, these types of study do not show whether the taught skills are used in routine clinical practice. More confidence can be placed in the results of roleplayed before and after training studies when improvements in clinician skills are accompanied by improved attitudes of GPs to these patients' problems (e.g. Gask et al. 1998) and if the skills are maintained over time (Bowman et al., 1992).

Studies of the use of clinical skills in routine general practice after training are difficult to perform and only practical for common mental health presentations such as somatised mental disorder (Blankenstein, 1998) or the evaluation of general interview skills (Goldberg et al., 1980).

Nevertheless, over the last two decades, several studies have demonstrated significant improvements in GPs' communication skills and their ability to recognise and manage psychological distress following mental health skills training (Goldberg et al., 1980; Bensing \& Sluijs, 1985; Whewell et al., 1987; Gask et al., 1987; 1988; 1989; 1998; Bowman et al., 1992; Kaaya et al., 1992). The important components of such training appear to be opportunities for video or audiotaped feedback of participants actual performance, opportunities to role-play in order to learn specific microskills and modelling of behaviours to be learned using specially prepared teaching videotapes based around a clear model of the skills and strategies to be acquired (Gask, 1998).

It has been also recognised, from the mixed findings of studies designed to improve recognition through screening, that simply focusing training on recognition alone, without also addressing the management of emotional disorders in primary care, is unlikely to bring about any considerable health gain. As Ormel \& Tiemens (1995) comment: ... The negative results stress the intrinsically close relationship of recognition and management skills. Without the latter, the objective of better recognition remains difficult to achieve.

It is likely that patients only benefit from the recognition of their mental disorder by the GP if the 
patient believes that the GP has a full understanding of their problems. In patients with somatised mental disorder in primary care, improvement in psychiatric symptoms was associated with the patient's perceived satisfaction with the GP's understanding or explanation of their problems (Downes-Grainger et al., 1998) rather than patient perceptions that the GP was disinterested or rejecting of their problems, or passively accepting the patient's view of their problems (Salman et al., 1999).

However, thus far it has not been easy to find conclusive evidence that training GPs in management skills does produce clear evidence of health gain. Catalan et al. (1984) showed that a brief psychological intervention by the GP after training was as equally effective as anxiolytic medication. Evans et al. (1987) demonstrated that patients of trained doctors were significantly more satisfied and had lower levels of anxiety after consultations compared to patients of untrained doctors. Neither of these studies, however, details whether there was any change in doctor behaviour following training, nor do they describe fully what form the training took. Roter et al. (1995) have reported some promising positive results for patients, evident up to six months follow-up, in a randomised controlled study of training for doctors in handling emotional distress. In our own study of the impact on patients with somatised emotional distress of training experienced GPs in 'Reattribution' techniques (Goldberg et al., 1989), we have found, using a before-after study design, promising economic benefits of training (Morriss et al., 1998) with clinical and social benefit limited to patients who, at least in part, accepted that their problems were emotional in origin (Morriss et al., 1999b). Follow-up was limited to 3 months and this work needs to be replicated in a randomised-controlled trial with a longer period of follow-up.

Other studies have, however been less promising. Putnan et al. (1988) found that residents were able to learn new skills from training in interviewing behaviours but that this had no effect on patient outcome. In Seattle, Lin et al. (1997) examined whether physician education had enduring effects on the treatment of depression and on depression outcomes. Results showed no lasting educational effect in any of the outcomes measured. Finally, in the best known study on the island of Gotland, Rutz et al. (1989a) reported that GPs identified more patients with depressive disorders and treated then more appropriately after provision of training. The suicide rate dropped the year after educational programmes were introduced and there was a decrease in both the utilisation of psychiatric inpatient care and the sick leave of depressed patients (Rutz et al., 1989b). However these all returned to baseline values after 3 years (Rutz et al., 1992).

What can we learn from these studies? Although the Gotland study is not directly comparable with the other work in that it did not focus on skill acquisition, it demonstrates the importance of ensuring that training effects can be maintained, with, if necessary, the provision of 'booster' sessions. In all the other studies, the follow-up period was much shorter. Skills training may also be more successful in producing positive outcomes for patients when it is not too ambitious in content and focuses on a realistic set of relatively easily learned skills (as in the «Reattribution' package (Goldberg et al., 1989). In general, studies of patient outcome after GP training have been too small, bearing in mind that effect sizes of training in patients are small. The unit of randomisation should be the GP rather than the patient because the GP or practice is the target of the training, which will further inflate the sample size approximately two fold (Dunn, 1994). Economic benefits of training may be easier to demonstrate when training is focused on patients who either consume a lot of health care such as somatising patients (Morriss et al., 1998) or are absent from work through illness but can return to work such as patients with milder anxiety or depressive disorders (Mynors-Wallis et al., 1997).

Training studies have only just started to examine whether there are benefits to the GP in terms of improved morale, improved confidence or growth in professional or personal development. The cost of training GPs might be worth paying if there were such benefits to GPs even if patients did not clinically benefit. There are some studies which show that GPs feel more confident about managing patients once they have learnt some specific management skills (Gask et al., 1998; Morriss et al., 1999b).

Lin et al. (1997) however rightly point out that training alone may be ineffective without paying more attention to both the organisation of services at the interface between primary and secondary care, and the value of systematic follow up to ensure that the GP's treatment benefited the patient. When physicians are trained to recognise and deal with patients more effectively, they also need to know what to do when they get out of their depth. There is a danger that GPs will be discouraged from using 
their newly learnt skills if GPs fear that they may uncover problems which they cannot manage and local secondary care services will ignore. Too little attention has, so far, been paid to the need for longerterm support and supervision yet it may be simplistic to expect to be able to provide a 'shot' of training and leave primary care workers to carry on alone. American studies have shown the benefits of the involvement of psychologists and psychiatrists together with patient self-help in supplementing the GP's care of depressed patients (Katon et al., 1996). However health care services in other countries probably cannot afford nor have access to such resources. An alternative is 'stepped care' in which patients are systematically followed up by the primary care team and given more intensive care by secondary care services if patients have made insufficient progress after a certain time period.

Recent reviews of the methods likely to be effective in continuing education for GPs (Davis et al., 1995; Smith et al., 1998) suggest that a range of strategies including academic detailing, targeting opinion leaders, systematic practice-based interventions and a combination of strategies or 'multifaceted interventions are more effective educational strategies than traditional methods such as lectures and conferences. Any strategy designed to bring about change must also pay attention to the environment and local context in which the intervention is to take place (Mays, 1994). What can those of us involved in developing training strategies for mental health skills in primary care learn from this work?

We do know already that only a limited number of doctors (in our experience about ten per cent of those approached) will be interested enough in mental health issues to attend a course outside their workplace. These numbers are of course greater if training is provided earlier and this has been the reasoning behind our attempts to specifically improve mental health skills training for medical students and for GP trainees (Creed, 1987; Ratcliffe et al., in press) and to train GP teachers themselves how to teach communication skills to their trainees (Gask et al., 1991; 1992).

However, considerably more experienced doctors can be reached (up to $35 \%$ ) if training is provided in the workplace, for the entire primary care team. There are other important advantages of this type of training such as the members of the primary care team learning how to support each other and developing guidelines and/or policy on the management of certain types of patient across the whole primary care team. However, we have found that training is often interrupted by routine service demands in the workplace, and as a result some GPs have difficulty in engaging fully with the training.

We have also found others workers such as nurses, where they work with doctors as part of a team, to be more readily enthusiastic about training and able to learn new skills (Morriss et al., 1999a), although there is still doubt about how most effectively to employ such skills in managing mental health problems once they have been acquired (Mann et al., 1998). When the training of nurses in the practice team is encouraged and supported by the GPs and other health professionals with mental health expertise e.g. community psychiatric nurses visiting primary care, the skills of practice nurses can be a useful resource to the primary care team. If such support is not available, practice nurses are discouraged from utilising these skills and it is likely that their skills decay over time.

Other doctors may be reached by offering a range of different strategies from videofeedback training at the highest level to those who are most committed (there is evidence that their skills can still be improved) through to academic detailing visits, reminders and patient-mediated interventions. These might be aimed at indirectly influencing what happens in the consultation by directly influencing patients locally via public information campaigns. The problem is that there is no evidence that these other interventions will be effective in developing skills. However, what they may do is serve as ways of getting doctors involved in mental health training, breach barriers and begin to support a primary care environment where there is an increased awareness of the need to develop such skills. Experience from the Defeat Depression Campaign which ran in the UK under the joint auspices of both the Royal Colleges of Psychiatry and of General Practice would suggest that local ownership of strategies, rather than campaigns which are perceived to be 'top down' and nationally or 'expert' led are more likely to be successful in breaking down such barriers.

This of course poses logistical problems. Such multifaceted, locally focused approaches are costly, time consuming and as yet have not been fully subjected to analysis in terms of clinical and economic benefits and costs. There is also a considerable skill shortage in terms of having the professionals available to organise and run such interventions. At a more basic level, there is still a considerable lack 
of skilled facilitators available to teach communication skills effectively using proven videofeedback techniques at either an undergraduate or postgraduate level.

Clearly more research is required in order to demonstrate the benefits of training in mental health skills but lessons from the existing research suggest that a broader approach, addressing the day-today difficulties not just at the interface with the patient but at the organisational interface between primary care workers and specialist mental health professionals may be needed. It has perhaps been naïve to expect longer-term health gains from training without addressing issues of skill retention, supervision and support. Approaches to education may need to be more flexible, offering a range of co-ordinated strategies across a district. Finally, more attention needs to be paid to development of the skills at all levels necessary to facilitate such effective training.

\section{REFERENCES}

Bensing J. \& Sluijs E.M. (1985). Evaluation of an interview training course for general practitioners. Social Science and Medicine 20, 737-744.

Blankenstein A.H. (1998). Feasibility of reattribution techniques applied to somatizing patients by general practitioners. 22nd European Conference on Psychosomatic Research, Manchester, 4th September 1998.

Bowman F., Millar T., Goldberg D., Gask L. \& McGrath D (1992). Improving the psychiatric skills of general practitioners: is the effect of training maintained? Medical Education 26, 63-68.

Catalan J., Gath D., Edmonds G. \& Ennis J. (1984). Effects of non-prescribing of anxiolytics I- controlled evaluation of psychiatric and social outcome. British Journal of Psychiatry 144, 593-602.

Creed F. (1987). Course in psychiatry for family doctors. Bulletin of the Royal College of Psychiatrists 11, 193-194.

Davenport S., Goldberg D. \& Millar T. (1987). How psychiatric disorders are missed during medical consultations. Lancet ii, 439-441.

Davis D.A., Thomson M.A., Oxman A.D. \& Haynes R.B. (1995). Changing physician performance: a systematic review of the effect of continuing medical education strategies. Journal of the American Medical Association 274, 700-705.

Downes-Grainger E., Morriss R., Gask L. \& Faragher B. (1998). Clinical factors associated with short-term changes in outcome of patients with somatised mental disorder in primary care. Psychological Medicine 28, 703-711.

Dunn G. (1994). Statistical methods for measuring outcomes. Social Psychiatry and Psychiatric Epidemiology 29, 198-204.

Evans B.J., Kiellerup F.D., Stanley O., Burrows. G.D. \& Sweet B. (1987). A communication skills programme for increasing patients' satisfaction with general practice consultations. British Journal of Medical Psychology 60, 373-378.
Gask L. (1998). Small group videofeedback teaching methods. International Journal of Psychiatry and Medicine 28, 97-113.

Gask L., McGrath G., Goldberg D. \& Millar T. (1987). Improving the psychiatric skills of established general practitioners: evaluation of group teaching. Medical Education 21, 362-368.

Gask L., Goldberg D., Lesser A.L. \& Millar T. (1988). Improving the psychiatric skills of the general practice traince: an evaluation of a group training course. Medical Education 22, 132-138.

Gask L., Goldberg D., Porter R. \& Creed F. (1989). The treatment of somatisation: evaluation of a training package with general practice trainees. Journal of Psychosomatic Research 33, 698703.

Gask L., Goldberg D., Boardman A.P., Craig T., Goddard C., Jones O., Kiseley S., McGrath G. \& Millar T. (1991). Training general practioners to teach psychiatric interviewing skills an evaluation of group training. Medical Education 25, 444-445.

Gask L., Usherwood T. \& Standart S. (1992). Training teachers to teach communication skills: a problem-based approach. Postgraduate Education for General Practice 3, 92-99.

Gask L., Usherwood T., Thompson H. \& Williams W. (1998). Evaluation of a teaching package for the assessment and management of depression in general practice. Medical Education 32, 190-198.

Goldberg D.P. \& Gater R. (1996). Implications of the World Health Organisation study of mental illness in general health care for training primary care staff. British Journal of General Practice 46, 483-485.

Goldberg D.P., Steele J.J. \& Smith C. (1980). Teaching psychiatric interviewing skills to family doctors. Acta Psychiatrica Scandinavica 62, 41-47.

Goldberg D.P., Gask L.\& O'Dowd T. (1989). The treatment of somatisation: teaching the skills of reattribution. Journal of Psychosomatic Research 33, 689-695.

Goldberg D.P., Jenkins L., Millar T. \& Faragher E.B. (1993). The ability of trainee general practitioners to identify psychological distress among their patients. Psychological Medicine 23, 185 193.

Kaaya S., Goldberg D.P. \& Gask L. (1992). Teaching the skills of 'reattribution' a replicated study. Medical Education 26, 138144.

Katon W, Robinson P., Von Korff M., Lin E., Bush T., Ludman E., Simon G. \& Walker E. (1996). A multifaceted intervention to improve treatment of depression in primary care. Archives of General Psychiatry 53, 924-932.

Kerwick S., Jones R., Mann A. \& Goldberg. D.P. (1997). Mental health training priorities in general practice. British Journal of General Practice 47, 225-227.

Lesser A.L. (1985). Problem-based interviewing in general practice: a model. Medical Education 19, 299-304.

Lin E.H., Katon W.J., Simon G.E., Von-Korff M., Bush T.M., Rutter C.M., Saunders K.W. \& Walker E.A. (1997). Achieving guidelines for the treatment of depression in primary care: is physician education enough? Medical Care 35, 831-842.

Lewis B. \& Gask L. (1994). Focus on Alcohol: Videotaped Training Package. Department of Postgraduate Medical Studies, University of Manchester: Manchester.

Mann A.H., Blizard R., Murray J., Smith J.A., Botega N., MacDonald E. \& Wilkinson G. (1998). An evaluation of practice nurses working with general practitioners to treat people with depression. British Journal of General Practice 95, 875-879.

Marks J.N., Goldberg D.P. \& Hillier V.F. (1979). Determinants of the ability of general paractitioners to detect psychiatric illness. Psychological Medicine 9, 337-353. 
Mays N .(1994). Changing clinician behaviour: do we know how to do it? In Health Care UK (1993-4) (ed. A. Harrison), pp. 102-117. King's Fund: London.

Morriss R., Gask L., Ronalds C., Downes-Grainger E., Thompson H., Leese B. \& Goldberg D. (1998). Cost-effectiveness of a new treatment for somatised mental disorder taught to general practitioners Family Practice 15, 19-25.

Morriss R., Gask L., Smith C. \& Battersby L. (1999a). Training practice nurses to assess and manage anxiety disorders: a pilot study. Nursing Times Research 2, 132-142.

Morriss R., Gask L., Ronalds C., Downes-Grainger E., Thompson H. \& Goldberg D.P. (1999b). Clinical and patient satisfaction outcome of a new treatment for somatised mental disorder taught to general practitioners. British Journal of General Practice 49, 263-267.

Morriss R., Gask L., Battersby L., Franceschini A. \& Robson M. (in press). An evaluation of a multidisciplinary training package to assess and manage patients at risk of suicide or deliberate self-harm. Journal of Affective Disorders.

Mynors-Wallis L., Davies I., Gray A., Barbour F. \& Gath D. (1997). A randomised controlled trail and cost analysis of problem solving treatment for emotional disorders given by community nurses in primary care. British Journal of Psychiatry 170, 113-119.

Ormel J. \& Tiemens B. (1995). Recognition and treatment of mental illness in primary care. Towards a better understanding of a multifaceted problem [editorial; comment]. General Hospital Psychiatry 17, 160-164.

Pereira Gray D. (1994). General practice and psychiatry: a general practice perspective. In Psychiatry and General Practice Today (ed. I Pullen, G. Wilkinson, A. Wright and D. Pereira Gray). Gaskell: London.

Putnam S.M., Stiles W.B., Jacob M.C. \& James S.A. (1988). Teaching the medical interview: an intervention study. Journal of General Internal Medicine 3, 38-47.

Ratcliffe J., Gask L., Creed F. \& Lewis B. (in press). Psychiatric training for family doctors: what do GP registrars want and can a brief course provide this? Medical Education.
Roter D.L., Hall J.A., Kern D.E., Barker L.R., Cole K.A. \& Roca R.P. (1995). Improving interviewing skills and reducing patients' emotional distress. A randomised clinical trial. Archives of Internal Medicine 155, 1877-1884.

Rutz W., von-Knorring L. \& Walinder J. (1989a). Frequency of suicide on Gotland after systematic postgraduate education of general practitioners Acta Psychiatrica Scandinavica 80, 151-154.

Rutz W., Walinder J., Eberhard G., Holmberg G., von-Knorring A.L., von-Knorring L., Wistedt B., Aberg-Wistedt A. (1989b). An educational program on depressive disorders for general practitioners on Gotland: background and evaluation. Acta Psychiatrica Scandinavica 79, 19-26.

Rutz W., von-Knorring L. \& Walinder J. (1992). Long-term effects of an educational program for general practitioners given by the Swedish Committee for the Prevention and Treatment of Depression. Acta Psychiatrica Scandinavica 82, 83-88.

Salmon P., Peters S. \& Stanley I. (1999). Patients' perceptions of medical explanations for somatisation disorders: qualitative analysis. British Medical Journal 318, 372-376.

Smith F., Singleton A. \& Hilton A. (1998). General practitioners' continuing education: a review of policies, strategies and effectiveness, and their implications for the future. British Journal of General Practice 48, 1689-1695.

Turton P., Tylee A. \& Kerry S. (1995). Mental health training needs in general practice. Primary Care Psychiatry 1, 197-199.

Üstün T.B. \& Sartorius N. (Ed.) (1995). Mental Health in General Health Care: An International Study. Wiley: New York.

Whewell P.J., Gore V.A. \& Leach C. (1988). Training general practitioners to improve their recognition of emotional disturbance in the consultation. Journal of the Royal College of General Practitioners 38, 259-262.

Williams K. (1988). Self-assessment of clinical competence by general practitioner trainees before and after a six-month psychiatric placement. British Journal of General Practice 48, 1387-1390. 